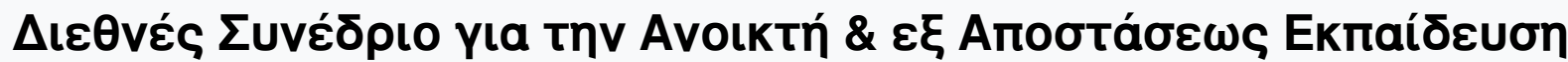

Tóp. 9, Ap. 6B (2017)

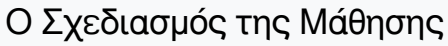

Tónos 6, Mépos B

\section{Практіка́}

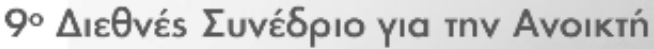

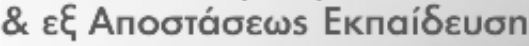

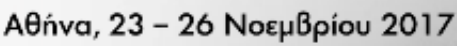

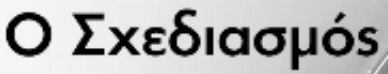
ins MáӨnons

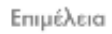

Avióvns Aıovapákns

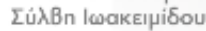

Mapia Niápn

「к⿱亠凶禸 $\mathrm{n}$ Mavoúoou

Tóvia Xaproqú

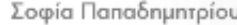

Avva Anoorodibou

ISBN 978.618.5335-01.4

ISBN SET 978-618-82258-5-5

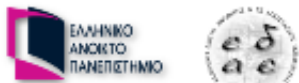

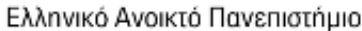

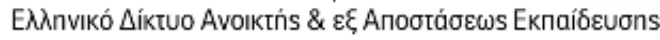

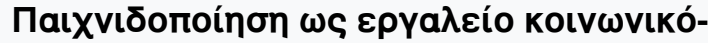

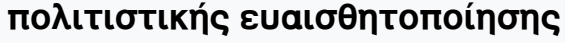

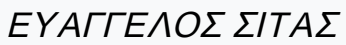

doi: $\underline{10.12681 / \text { icodl. } 1123}$ 


\title{
Gamification as tool to raise sociocultural awareness
}

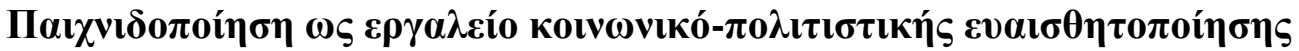

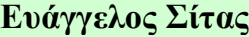 \\ Phd Candidate \\ University of the Basque Country

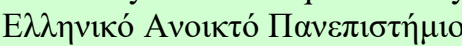 \\ vagsit@gmail.com
}

\begin{abstract}
In this article, we will be using gamification as a tool to generate more engagement with the user and raise his social understanding and cultural awareness. We will underline the fact that the field of games for learning is now mature and that play and identities construction can work together.

In this direction, we come to the following question: how people could learn best digitally? Nowadays, digital games have emerged from the background to the foreground of our cultures, playing a key role to an increasing area of purposes. To give an answer to this question, a few examples will be presented here, i.e. games from the United Nations website, which offer intercultural experiences and aim to develop socio-cultural awareness.
\end{abstract}

Keywords: gamification, serious games, sociocultural awareness, self-determination theory, narratives

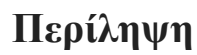

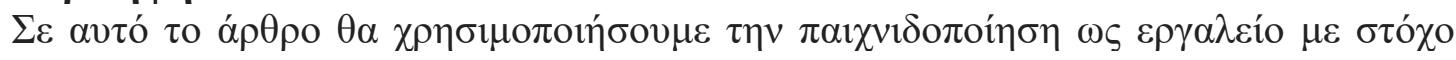

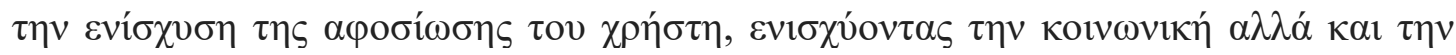

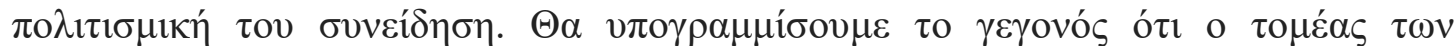

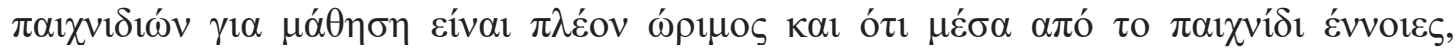

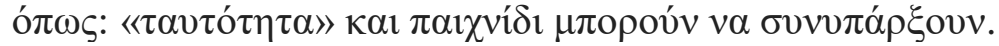

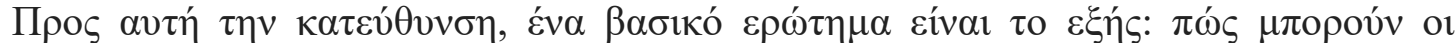

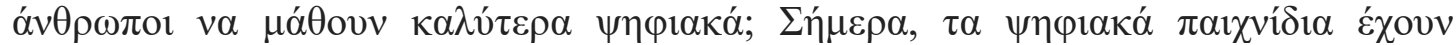

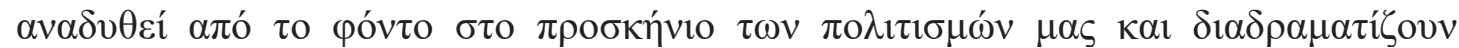

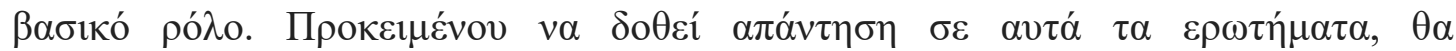

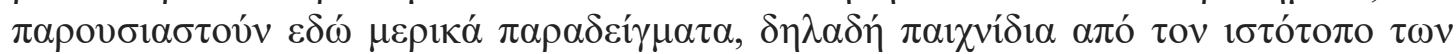

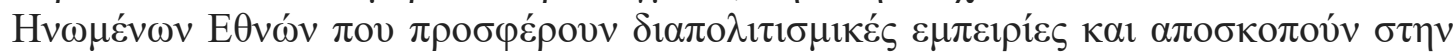

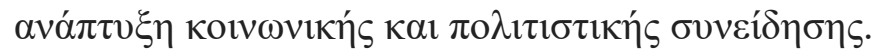

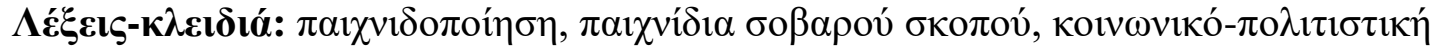

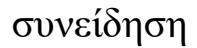

\section{Introduction}

Few years ago, at the Games Learning Society conference, game designer Eric Zimmerman (2013), writing his "Manifesto for a Ludic Century", eloquently inquired 
whether the twentieth-century information age, might be followed by a ludic age. Now as we move towards the 21 st century, we witness that the world has undergone major shifts that, maybe, a decade earlier would seem unthinkable. Perhaps, a playful specter is haunting the world, (Raessens, 2006).

In the very beginning of our century, games were considered a "waste of time" with latent addictive consequences and none of us had ever heard the term "gamification". Nevertheless, when the ubiquitous features of games began to emerge, everyone realized that games are powerful and that they can be used as an engagement tool. The term gamification was a catalyst term, that triggered a short of a chain reaction, reminding us that we are already living in a gameful world. In fact, games slowly became the media paradigm of the 21st century (Flanagan \& Nissenbaum, 2014). Since then, game studies, game design courses and other similar products, related to the lucrative business of games, began to emerge rapidly.

Our debate starts by posing ourselves a set of questions to gain more insight of our gameful present and our ludic future: Is there a way to delimit this cultural swift? Could socio-cultural awareness be triggered by a video game lead to behavioral change in the long run? Should this be true, is this behavior transferable to the real world? The aforementioned questions will be supported by the increased interest of the United Nations initiative regarding serious games, which are related to migration. Could new ways of behavior be developed through these games?

In this article, our attention will not revolve around the "basics" of gamification, since we are taking for granted that the term is no longer a buzzword or a passing millennial trend; nor will we perceive gamification as a deus ex machina, providing a solution to the roadblock of any social or educational challenge. The focus of this article is to underline the fact that gamification can be effective and produce behavior change and second, to reveal the complex relationship between gamification, play and identity or what Raessens (2006) describes as a playful identity. Moreover, taking a closer look to Darvasi's report we can see that "serious games" can alter and create cognitive empathy, a necessary skill if we want to raise socio-cultural awareness.

Through some refugee games that we will be presented, we will be discussing the potential outcomes of gamification by implementing storytelling and immersive game scenarios to infuse social awareness. We are living in a world of games and gamers, thus, engagement matters. Given the fact that storytelling acts are crucial for the plot of a video game, we will be examining also why narratives can foster motivation.

\section{The future of learning}

The dynamic nature of our era promises a collapse of the remaining learning and educational boundaries, given the fact that both are more likely to occur outside than inside the traditional institutions, a forecast that brings up a new educational avenue, where none of us can know everything, each of us knows something; but combining our resources and skills we can put the pieces of a puzzle together. Lévy (1997) describes this as collective intelligence. Learning has become a collective process as consumption, giving birth to a new form of interaction, regarding almost every aspect of our lives, shifting towards a culture of convergence. Videogames or online gaming are a very good example.

Convergence can be witnessed in so many ways and in so many contexts, given the fact that current digital environments have become more dominant than ever before. Therefore, for the purposes of this article, we use Jenkins (2006) theory of convergence as a compass, to explore how the different dimensions of our world are changing and how all of us are shaping the future of learning. Jenkins (2006) 
describes his conception of converging culture and welcomes us to a cultural shift by using the following definition:

as the flow of content across multiple media platforms, the cooperation between multiple media industries, and the migratory behavior of media audiences that will go almost anywhere in search of the kinds of entertainment experiences they want, where old and new collide at an intersection, where a new form of interaction between the producer and the consumer emerges and where everything is decomposed and recomposed in unpredictable ways, where digital immigrants find digital natives (pp. 2-4, 17-18, 258-260).

Deterding (2014) argues that games are now available in every digital device and that game distribution has migrated from off-the-shelf physical copies to online streaming. As a result, we witness a shift from finished products to online services, where thousand transactions, economic or not, are being held every day. This form of gaming convergence announces what several authors, such as (Walz, 2006; Stentros Montola \& Mäyrä, 2007) call ludification of culture or the rise of a ludic society

\section{Games in contemporary culture}

Games have reached a point to our cultures that almost everyone nowadays, accepts the fact they are a big deal and that, day after day, are becoming an ever more ubiquitous element of daily life, as Tadsen (2016) states. According to him, taking a closer look to this phenomenon, reveals that videogames are increasingly being converted into a cultural currency for an increasing area of purposes; they are played, referenced, politicized or monetized. Culture nourishes both game designers and players. For the designers, it is a resource that can be incorporated into games and for the other local gaming practices and specific social contexts can affect their playing experiences (Tadsen, 2016). In other words, game's components and players' performance do matter.

Even if games appear in almost every digital device, there are still some people that perceive the future in terms of the past. They greet the change, described above, with skepticism or, even worse, they are amazingly indifferent about the potential of games. Meanwhile, the Entertainment Software Association annual report (ESA, 2015) reminds us that the revenue of gaming industry is approximately 22.40 billion in 2015 and that in every U.S household there is an average of two gamers. Play is deeply rooted in human life, not only for humans, but also for animals.

According to Bauman (1995) everyone, human or animal, has played, in all cultures and in all times. In the ludic culture we are living, we see that playfulness is no longer attributed specifically to childhood, but on the contrary, we can see that lifelong characteristics are now applied. The polish sociologist and philosopher argues that human identity has even become a playful phenomenon and that the mark of postmodern adulthood is the willingness to embrace the game whole-heartedly, as children do (Bauman 1995).

Skeptics would say that playfulness characterizes leisure time or that games are a waste of time or loss of real life. Nevertheless, playfulness characterizes also these sectors that decades ago, were considered as more serious, such as education, health, business, army, politics. Nowadays, these domains are the ones that increase gamifications' revenue. Serious games can be applied as an umbrella term for any game-based initiative that has an additional, 'serious' agenda. Although these two words brought together arise contradiction, the truth is different.

Serious games are not a new phenomenon since almost in 1970, researcher Clark C. Abt coined the term, after publishing the book Serious Games. Thirty years later, in 
2000, we have the Serious Games Initiative (SGI) brought by Ben Sawyer, a game developer SGI tries to provide an institutional context for this kind of game application (Wilkinson, 2016). Nowadays, there are many organizations providing an umbrella for serious gaming, as described earlier. In fact, according to Rifkin (2001), play is becoming as important in the cultural economy as work was in the industrial economy, but the question that underlines here is the following: do we play just for fun or does play have other functions in our lives? This is where Play Theory attempts to answer these kinds of questions.

Cultural historian Johann Huizinga in his book Homo Ludens (1936) argues that play is not a frivolous activity, but, on the contrary, it is maybe one of the basic ingredients of culture.

(Huizinga, 2014) «The rules of warfare, the conventions of noble living were built up on play-patterns. We must conclude, therefore, that civilization is, in its earliest phases, played. It does not come from play like a babe detaching itself from the womb: it arises in and as play, and never leaves it. » (p. 173)

Nevertheless, Huizinga doesn't mention that cultures will keep playing, since he highlighted that all cultures, as humans, play in their youth, but as they grow old and mature, they tend to lose the initial playfulness. Huizinga died in 1945, so we should consider the general historical period since little room for play would there be at that time. And even if, in the last pages of his book, he states that the play element in the 20th century is on the wane and that civilization to-day is no longer played, we dare to challenge this assumption. Today, civilization is more mature regarding play than ever before.

McGonigal (2011) states that those who continue to write off games will be less prepared to shape the future and, therefore, will miss some of the most promising opportunities to create new experiences.

\section{Games that build socio-cultural understanding: a few examples}

During the last few decades, serious games have addressed all kinds of political problems to raise awareness regarding what is like to be a refugee or what does it need to the humanitarian aid succeeds. Earlier, we argued that games can positively affect others and that in the long run, are capable for raising social awareness to become more politically involved. In this section, we present a few examples of games from the United Nations official website, that belong to the serious games category as mentioned earlier.

The main objectives of these games are to raise socio-cultural awareness. For this purpose, the United Nations system turned to video games as a solution, through which the most affluent nations will raise awareness, from the hunger problem to the refugee's crisis. In fact, the UN is trying to take advantage one of the most important attributes of games: the fact that they can place us in the shoes of other people. The games that we will be presenting here have a specific purpose, a specific context, and are addressed to a specific problem. Furthermore, they are designed to have a huge impact on the player by showing the long-term consequences to the real world.

Here is a list of some games, aimed for ages mainly between 12 and 16, brought from the United Nations website:

- Stylista - WFP (World food Programme) Age: $12+$

- Against All Odds (UNHCR) Age: 12 to 15

- Fast Car: Travelling Safely around the World (UNESCO) Age: 16 to 24

- get to ZERO Age: $12+$

- $\quad$ Mind the Gap (UNESCO) Age: $12+$ 
- STOP Disasters (UN/ISDR) Age: 9 to 11

- Free Rice 2.0 (WFP) Age: 12+

- Food Force (WFP) Age: $12+$

These games in the list share the following common objectives: they strive to develop understanding and tolerance towards immigrants, to increase social interaction and collaboration amongst different national groups. For example, «Stylista» is the first Facebook game to support WFP's emergency response in Syria; «Against All Odds» gives the player the possibility to take the role of a refugee through twelve stages, contemplating the same decisions refugees make in real life from persecution; «Fast Car»: travelling Safely around the World, aims to inform young people with reliable information about HIV in order to promote healthier behavior; "Get to ZERO» is a game trying to end hunger and in order to reinforce this belief a common cause is created. Hunger can only get to zero if we try all together. In this game, the user also gets a prize, a UN virtual passport that is shareable to social media. «Mind the gap» is another data game brought from UNESCO. By creating an avatar, the player is virtually taking a trip to learn about the inequalities in education. «STOP Disasters» is another game, part of the World Disaster Reduction Campaign aimed to teach children how to build safer villages against disasters. Finally, «Free Rice» and «Food Force» are, maybe, the best examples of what gamification is capable of. Up to the present time, over 90 billion grains are donated. For every right answer, the player donates 10 grains of rice through the World Food Program initiative. On the other hand, Food Force has been downloaded over 6 million times. With an estimated network of 10 million players worldwide, we can imagine the social impact that these games can have in the long run. According to WFP blog, "money players spent funds meals in the real world by providing daily meals to 20 million children every year" Raessens, 2006, p. 251). In a world that is becoming more complex, videogames can fill the gap of civic engagement. From games with a simple design to more complex ones, the player becomes involved in the real world by playing the game.

\section{Narratives: Concluding thoughts}

Earlier, we discussed the societal challenges, arising from the converged culture, amplified by a generation hard wired to games. Another characteristic, that is quite common in a gamer's brain, is that when the story of a game is compelling, even if it is not close to the players experience, a short of emotional bond, tied to the game and the gaming community, is activated. The player identifies himself inside the game. In other words, the game is converted into an extension of our own perspective, giving us the choice to speak through it, through an avatar for example. Thus, playing a game means interacting with and within a representational universe, a space of possibility with narrative dimensions (Salen \& Zimmerman, 2004, p. 378). Formed by rules and experienced through play, a game is a space of possible action, that players activate, manipulate, explore and transform (Salen \& Zimmerman, 2004, p. 378).

The value of this space should not be underestimated because, through the narrative space of games, we can build a strong personal or a cultural identity. Here, the vantage point is Self Determination Theory (SDT) (Deci \& Ryan, 1985; Ryan \& Deci, $2000 \mathrm{~b}$ ), that, in short, claims that people have three innate psychological needs, that are considered as universal necessities. From the three psychological needs, that comprise SDT, competence, autonomy, and relatedness, here we will be taking a closer look to relatedness.

Relatedness is experienced when a person feels connected with others (La Guardia, Ryan, Couchman, \& Deci, 2000; Ryan \& Deci, 2001). Relatedness describes a 
powerful motivator, because of our innate need not to feel alone. We need to interact with each other and experience support from others and feel that we matter, feel connected without ulterior motive. Thus, it is possible to cultivate empathy and intercultural understanding. In fact, Adachi, Hodson, and Hoffarth (2015) concluded that video games can be used to boost empathy, outgroup knowledge and, above all, reduce prejudice toward outgroups. These concepts are all crucial to frame a new global citizen (Palaiologou and Dietz, 2012).

One more interesting aspect of the three elements of SDT is how much all of them are related not to extrinsic motivations but intrinsic ones and, more specifically, to find meaning. We assume that the need for social relatedness can be triggered and sustained, when a story offers a compelling narrative frame, even more, if in the player has a protagonist and meaningful role in the story. Even if, about a decade ago, early digital games did not have a complex narrative, nowadays, modern and online games facilitate strong relationships and group ties. Modern games contain complex narrative structures and, in story-driven games, players are granted the opportunity to explore a plot like a novel (Klimmt, 2009).

Concluding, in this paper through a few examples-games from the United Nations, which were presented here, we tried to highlight the importance and impact of the new informal ways of long distance learning, which set cultural objects can increase socio-cultural awareness, and frame a new global citizen (Palaiologou \& Dietz, 2012). In the next years to come, games, in general, will be completely different thanks to the frenetic advances of digital technology. Even if there is room for improvement for both virtual and augmented reality, in a few years from now, they will be the norm. In this paper, we learned that serious games can help others to learn something regarding a specific context. The next level of video games and serious games will grant us the possibility to feel. We will not be playing through our mobile device anymore, since virtual reality or holographic equipment are expanding, bringing more possibilities and emotions to the player through more immersive scenarios.

Maybe video games will not change human nature after all, but it will be up to us, if we use these promising unforgettable emotions, that games offer, not only to raise social and cultural awareness, but to sustain it.

\section{References}

Adachi, P. J., Hodson, G., \& Hoffarth, M. R. (2015). Video game play and intergroup relations: Real world implications for prejudice and discrimination. Aggression and violent behavior, 25, 227-236.

Bauman, Z. (1995). Life in fragments: Essays in postmodern morality.

Darvasi, P. (2016). How Digital Games can Support Peace Education and Conflict Resolution (Working Paper). Retrieved from: Mahatma Gandhi Institute of Education for Peace and Sustainable Development / UNESCO website: http://mgiep.unesco.org/wpcontent/uploads/2016/12/WORKING-PAPER-PAUL-DARVASI-.pdf

Deci, E. L., \& Ryan, R. M. (1985). Intrinsic motivation and self-determination in human behavior. New York: Plenum.

Deterding, S. (2014). The ambiguity of games: Histories and discourses of a gameful world. The Gameful World: Approaches, Issues, Applications, p. 23, 2015.

Huizinga, J. (2014). Homo Ludens Ils 86 (Vol. 3). Routledge.

Jenkins, H. (2006). Convergence culture: Where old and new media collide. NYU press.

Klimmt, C. (2009). Serious games and social change: Why they (should) work. Serious games: Mechanisms and effects, 248-270.

La Guardia, J. G., Ryan, R. M., Couchman, C. E., \& Deci, E. L. (2000). Within-person variation in security of attachment: a self-determination theory perspective on attachment, need fulfillment, and well-being. Journal of personality and social psychology, 79(3), 367. 
Lévy, P. (1997). Collective intelligence. New York: Plenum/Harper Collins.

McGonigal, J. (2011). Reality is broken: Why games make us better and how they can change the world. Penguin.

Palaiologou, N., \& Dietz, G. (Eds.). (2012). Mapping the broad field of multicultural and intercultural education worldwide: Towards the development of a new citizen. Cambridge Scholars Publishing.

Raessens, J. (2006). Playful identities, or the ludification of culture. Games and Culture, 1(1), 52-57.

Rifkin, J. (2001). The age of access: The new culture of hypercapitalism. Penguin.

Ryan, R. M., \& Deci, E. L. (2000b). Self-determination theory and the facilitation of intrinsic motivation, social development, and well-being. American Psychologist, 55, 68-78.

Salen, K., \& Zimmerman, E. (2004). Rules of play: Game design fundamentals. MIT press.

Stenros, J., Montola, M., \& Mäyrä, F. (2007, November). Pervasive games in ludic society. In Proceedings of the 2007 conference on Future Play (pp. 30-37). ACM.

Suits, B. (2014). The Grasshopper-: Games, Life and Utopia. Broadview Press.

Tadsen, P. (2016). Cultural Code: Video Games and Latin America. MIT Press.

Walz, S. P., \& Deterding, S. (Eds.). (2015). The gameful world: Approaches, issues, applications. Mit Press.

Wilkinson, P. (2016). A brief history of serious games. In Entertainment computing and serious games (pp. 17-41). Springer International Publishing.

Zimmerman, E. (2015). Manifesto for a ludic century. The gameful world: Approaches, issues, applications, 19-22.

Entertainment Software Association (ESA). (2015). Essential facts about the computer and video game industry (p. 3-7). Retrieved from http://essentialfacts.theesa.com/EssentialFacts-2015.pdf 